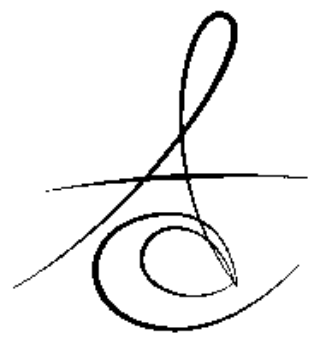

\title{
OBSTRUKTİF UYKU APNESİ SENDROMU AÇISINDAN YÜKSEK RİSKLİ BİREYLER İLE DÜŞÜK RİSKLİ BİREYLER ARASI SİNO-NAZAL BÖLGEDE ANATOMİK VARYASYON VE PATOLOJİ GÖRÜLME SIKLIĞININ KARŞILAŞTIRILMASI
}

\author{
A COMPARISON OF ANATOMICAL VARIATIONS AND PATHOLOGIES \\ PREVALENCE IN SINO-NASAL REGION BETWEEN THE PATIENTS AT HIGH \\ RISK AND LOW RISK FOR OBSTRUCTIVE SLEEP APNEA SYNDROME
}

\author{
Yrd. Doç. Dr. Mehmet Zahit ADIŞEN ${ }^{*}$ Yrd. Doç. Dr. Melda MISIRLIOĞLU*
}

Makale Kodu/Article code: 2053

Makale Gönderilme tarihi; 07.01.2015

Kabul Tarihi: 25.02.2015

\section{ÖZET}

Amaç: Bu çalışmanın amacı Obstrüktif Uyku Apne Sendromu için yüksek riskli ve düşük riskli olarak belirlenen bireyler arasında, sino-nazal bölgede anatomik varyasyon ve patoloji görülme sıklığının, konik ışınlı bilgisayarlı tomografi görüntüleri kullanılarak karşılaştırılmasıdır.

Gereç ve Yöntem: Çalışmamız Kırıkkale Üniversitesi, Diş Hekimliği Fakültesi, Ağız Diş ve Çene Radyolojisi Anabilim Dalı'nda, Ocak-Haziran 2014 tarihleri arasında kliniğimize rutin muayeneye gelen, 18-30 yaş aralığındaki 50 genç erişkin hasta ile yapıldı. Her hasta için kimlik bilgilerini, sigara anamnezini, Berlin Anketi ve Epworth Uykululuk Ölçeği'ni içeren hasta bilgi formu dolduruldu. Hastaların anketlere verdikleri cevaplara göre 25 yüksek riskli, 25 düşük riskli hasta belirlendi. Radyolojik ölçümler için hastalardan konik ışınlı bilgisayarlı tomografi görüntüleri alındı.

Bulgular: Epworth skoru ve sigara kullanım oranı risk grupları arasında anlamlı olarak farklılık gösterdi. Sinonazal bölgede anatomik varyasyon ve patoloji varlığı açısından gruplar arası istatistiksel olarak anlamlı bir fark bulunmadı. Ancak yüksek riskli hasta grubunda düşük riskli hasta grubuna göre maksiller sinüs mukozasında kalınlaşmaya daha sık rastlandı.

Sonuç: Çalışma sonuçlarına göre sinonazal bölge anatomik varyasyon ve patolojilerinin Obstrüktif Uyku Apnesi için primer risk faktörü olarak değerlendirilemeyeceği ve nazal cerrahinin sadece seçili hastalara uygulanması gerektiğini düşünmekteyiz.

Anahtar kelimeler: Uyku apnesi sendromu, konik ışınlı bilgisayarlı tomografi, maksiller sinüs, nazal kavite

\section{ABSTRACT}

Aim: The aim of the present study is to compare the prevalence of anatomical variations and pathologies of sino-nasal region between the patients at high risk and low risk for Obstructive Sleep Apnea Syndrome by using cone-beam computed tomography.

Material and Method: The study was performed in 50 patients, age of $18-30$ years, referred to Kırıkkale University, Faculty of Dentistry, Department of Oral and Maxillofacial Radiology between January-June 2014 for routine dental examination. Surveys that include identity information, smoking history, the Berlin Questionnaire and the Epworth Sleepiness Scale were filled with the patients. According to their answers 25 patients were determined as low risk and 25 were determined as high risk. Cone-beam computed tomography images were obtained for radiological examinations.

Results: There were significant differences between risk groups for Epworth score and smoking ratio. Whereas, no differences were found for the prevalence of anatomical variations and pathologies on sino-nasal region except for mucosal thickening in maxillary sinuses.

Conclusion: Anatomical variations and pathologies on sino-nasal region should not be considered as a primary risk factor for Obstructive Sleep Apnea. Nasal surgery should only be performed on specific cases.

Keywords: Sleep apnea syndrome, cone-beam computed tomography, maxillary sinus, nasal cavity.

* Kırıkkale Üniversitesi, Diş Hekimliği Fakültesi, Ağız Diş ve Çene Radyolojisi 


\section{GİRİş}

Obstrüktif uyku apnesi sendromu (OUAS) uyku sırasında tekrarlayan solunum duraklamaları (apne) veya hava akımı değerinin azalması (hipopne) ile karakterize bir hastalıktır. Prevalansı erişkinlerde \%1-4 arasında değişmektedir. Önlem alınmadığı takdirde ölümle sonuçlanabilir. ${ }^{1}$ Hastalığın bu denli ciddi sonuçları olduğu toplum içinde çok fazla bilinmez. Birey genellikle hastalığın farkında olmadığından veya önemsemediğinden hekime gitmez. ${ }^{2}$

OUAS'lı hastalarda normal bireylere göre üst solunum yollarında (ÜSY) önemli farklılıklar bulunur ve hava yolu kollapsı hastaların \%75'inden fazlasında retropalatal bölgede meydana gelir. ${ }^{3}$ Bunun dişında nazal bölgede meydana gelen obstrüksiyonlar da hava akım rezistansında artışa ve solunum zorluğuna neden olur. $\mathrm{Bu}$ obstrüksiyonlar ise genellikle mekanik (septum deviasyonu, konka bülloza, konka hipertrofisi) ya da enflamatuar (akut/kronik rinit) nedenlere bağlı oluşur ve OUAS için risk teşkil eder. ${ }^{4}$

OUAS tanısında altın standart yöntem polisomnografi (PSG)'dir. PSG gece uykusu boyunca hastanın beyin dalgalarının, göz hareketlerinin, solunum faaliyetlerinin, kanındaki oksijen yüzdesinin ve kas aktivitesinin ölçülmesi ile yapılan incelemenin adıdır. ${ }^{5,6}$ PSG'nin zaman alıcı olması, maliyetinin yüksek olması, özel bir ekip gerektirmesi yanında ülkemizde ve dünyada uyku çalışması yapacak yeterli sayıda laboratuvarın olmaması riskli hastaların belirlenmesini önemli kılar. Bu nedenle hastalığın teşhisinde klinik ve radyografik bulgular ile bunlara dayalı anketler yol göstericidir. Standart anketler PSG için doğru hasta seçiminin yanı sıra bilimsel çalışmalarda ortak dil kullanımı açısından da yarar sağlar ve PSG yapılmak üzere doğru olgu seçimine yardımcı olurlar. Radyografik incelemeler ise obstrüksiyon bölgesinin belirlenmesi ve ameliyat öncesi tedavi planlamasında kullanılırlar. ${ }^{7}$

$\mathrm{Bu}$ çalışmanın amacı OUAS toplum taramalarında kullanılan anketlerden Berlin Anketi (BA) ve Epworth Uykululuk Ölçeği (EUÖ)'ne göre yüksek ve düşük riskli olarak tespit edilen genç bireylerin konik ışınlı bilgisayarlı tomografi (KIBT) görüntülerinde sinonazal bölgede anatomik varyasyon ve patoloji görülme sıklığının karşılaştırılmasıdır.

\section{MATERYAL METOD}

Bu çalışma, Kırıkkale Üniversitesi, Diş Hekimliği Fakültesi, Ağız Diş ve Çene Radyolojisi Anabilim Dalı'nda Ocak-Haziran 2014 tarihleri arasında gerçekleştirilmiş ve Kırıkkale Üniversitesi İlaç Dışı Klinik araştırmalar Etik Kurulu 6/4 nolu kararıyla onaylanmıştır.

Çalışma grubu kliniğimize rutin muayeneye gelen 18-30 yaş aralığındaki genç erişkin hastalardan çalışma kriterlerine uygun olan 50 hasta ile oluşturuldu. Hastalara çalışma hakkında bilgi verildi. Çalışmaya katıldıklarına dair yazılı onamları alındıktan sonra kimlik bilgilerini, ek hastalıklarını, sigara anamnezini, BA ve EUÖ'ni içeren hasta bilgi formu dolduruldu (Tablo 1, 2). Anketlerin doldurulma işlemi, hastaların beraber ikamet ettikleri eş, akraba veya ev arkadaşı gibi bir yakınları ile birlikte gerçekleştirildi. Hastaların anketlere verdikleri cevaplara göre 25 yüksek riskli (EUÖ >10, BA 3 kategoriden 2'si +) ve 25 düşük riskli (EUÖ <10, BA 3 kategoriden 1'si + veya hepsi -) hasta belirlendi.

\section{Hasta seçim kriterleri}

- Santral uyku apnesine sebebiyet verebilecek;

- Santral sinir sistemi hastalığı bulunmayan, (Epilepsi, ensefalit, beyin sapı tümörü, psikiyatrik bozukluk vb.)

- Kalp yetmezliği ve kalp krizi hikâyesi bulunmayan, (Cheyne-stokes solunumu ile ilişkili olarak)

- Solunum sistemi hastalığı bulunmayan, (astım, bronşit, KOAH vb.)

- Kas zayıflığına neden olacak bir hastalığı bulunmayan, (Myastenia Gravis, Musküler distrofi vb.)

- Uzun süreli yüksek irtifada yolculuk etmiş olmayan,

- Santral sinir sistemine etkisi olan ilaç kullanıyor olmayan, (Narkotikler, barbitüratlar, antidepresanlar vb.)

- Hamilelik durumu bulunmayan,

- Metabolik hastalığı bulunmayan, (Diyabet, böbrek yetmezliği vb.)

- Nazal obstrüksiyona sebebiyet verecek geçirilmiş travma ve ameliyat hikayesi olmayan hastalar çalışmaya dahil edildi. 
Tablo 1. Berlin Anketi

\begin{tabular}{|c|c|c|}
\hline Kategori 1 & Kategori 2 & Kategori 3 \\
\hline $\begin{array}{ll}\text { Soru 1: Horlar mısınız? } \\
\square & \text { Evet } \\
\square & \text { Hayır } \\
\square & \text { Bilmiyorum }\end{array}$ & $\begin{array}{l}\text { Soru 6: Ne sıklıkta } \\
\text { uyku sonrası yorgun } \\
\text { veya halsiz } \\
\text { hissedersiniz? } \\
\square \text { Hemen her gün } \\
\square \text { Haftada 3-4 gün } \\
\square \text { Haftada 1-2 gün } \\
\square \text { Hiç veya hemen } \\
\text { hemen hiç }\end{array}$ & $\begin{array}{l}\text { Soru 10: Yüksek } \\
\text { tansiyonunuz var mı? } \\
\square \text { Evet } \\
\square \text { Hayır } \\
\square \text { Bilmiyorum }\end{array}$ \\
\hline $\begin{array}{l}\text { Soru 2: Horluyorsanız: } \\
\text { Nefes alıp vermekten } \\
\text { biraz daha gürültülü } \\
\text { Konuşmak kadar } \\
\text { gürültülü } \\
\text { Konuşmaktan daha } \\
\text { gürültülü } \\
\text { Çok gürültülü, komşu } \\
\text { odalardan duyulabilir }\end{array}$ & $\begin{array}{l}\text { Soru 7: Uyanık } \\
\text { olduğunuz zaman } \\
\text { süresince yorgunluk } \\
\text { veya uykulu } \\
\text { hissediyor musunuz? } \\
\square \text { Hemen her gün } \\
\square \text { Haftada 3-4 gün } \\
\square \text { Haftada 1-2 gün } \\
\square \text { Ayda 1-2 gün } \\
\square \text { Hiç veya hemen } \\
\text { hemen hiç }\end{array}$ & $\begin{array}{l}\text { VÜCUT KİTLE } \\
\text { İNDEKSİ: } \\
\text { Boy: } \\
\text { Kilo: } \\
>30=\text { Riskli }\end{array}$ \\
\hline $\begin{array}{l}\text { Soru 3: Ne sıklıkta } \\
\text { horlarsını? } \\
\text { Hemen her gün } \\
\text { Haftada 3-4 gün } \\
\text { Haftada 1-2 gün } \\
\text { Hiç veya hemen hemen } \\
\text { hiç }\end{array}$ & 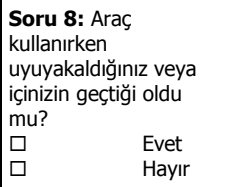 & \\
\hline $\begin{array}{l}\text { Soru 4: Horlamanız } \\
\text { nedeni ile diğer insanları } \\
\text { rahatsı ettiğiniz oldu } \\
\text { mu? } \\
\text { Evet } \\
\text { Hayır }\end{array}$ & 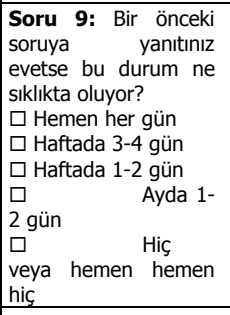 & \\
\hline $\begin{array}{l}\text { Poru 5: Uykunuz sırasında } \\
\text { hefesinizin durduğu başka } \\
\text { iri tarafından fark edildi } \\
\text { ni? } \\
\text { Hemen her gün } \\
\text { Haftada } 3-4 \text { gün } \\
\text { Haftada } 1-2 \text { gün } \\
\text { Ayda } 1-2 \text { gün } \\
\text { Hiç veya hemen hemen } \\
\text { hiç }\end{array}$ & & \\
\hline
\end{tabular}

Berlin Anketi'nde hastalara 3 kategoride 10 soru sorulmakta, verilen cevaplara göre kategori riskli/riskli değil olarak değerlendirilmektedir. 3 Kategorinin en az 2'sinden riskli olarak tespit edilen hastalar OUAS için riskli olarak kabul edilmektedir.
Tablo 2. Epworth Uykululuk Ölçeği

\begin{tabular}{|l|l|l|l|l|}
\hline $\begin{array}{l}\text { Aşırı yorgun olmadığınız bir } \\
\text { günde aşağıdaki durumlarda } \\
\text { uykuya dalma olasılığınız } \\
\text { nedir? }\end{array}$ & Hiç & Bazen & $\begin{array}{l}\text { Genell } \\
\text { ikle }\end{array}$ & $\begin{array}{l}\text { Her } \\
\text { zama } \\
\text { n }\end{array}$ \\
\hline $\begin{array}{l}\text { 1. Oturur durumda gazete veya } \\
\text { kitap okurken }\end{array}$ & 0 puan & 1 puan & 2 puan & 3 puan \\
\hline 2. Televizyon seyrederken & 0 puan & 1 puan & 2 puan & 3 puan \\
\hline $\begin{array}{l}\text { 3. Pasif olarak toplum içinde } \\
\text { otururken (tiyatro, toplantı, vb....) }\end{array}$ & 0 puan & 1 puan & 2 puan & 3 puan \\
\hline $\begin{array}{l}\text { 4. Aralıksız 1 saatlik araç yolculuğu } \\
\text { yaparken }\end{array}$ & 0 puan & 1 puan & 2 puan & 3 puan \\
\hline 5. Öğleden sonra uzanınca & 0 puan & 1 puan & 2 puan & 3 puan \\
\hline $\begin{array}{l}\text { 6. Alkolsüz bir öğle yemeğinden } \\
\text { sonra otururken }\end{array}$ & 0 puan & 1 puan & 2 puan & 3 puan \\
\hline 7. Birisi ile konuşurken & 0 puan & 1 puan & 2 puan & 3 puan \\
\hline $\begin{array}{l}\text { 8. Araç kullanıkken birkaç dakika } \\
\text { trafik durduğunda } \\
\text { (kırmızı ışık, kalabalık trafik...) }\end{array}$ & 0 puan & 1 puan & 2 puan & 3 puan \\
\hline
\end{tabular}

Epworth Uykululuk Ölçeğinde hastalara 8 soru sorulmakta ve verilen cevaplara göre skorlama yapılmaktadır. Toplam 10 puan ve üzeri gündüz aşırı uykululuğa işaret etmektedir.

Radyolojik inceleme için Pax Uni3D (Vatech, Seoul, Korea) cihazı ile hastalardan sino-nazal bölge KIBT görüntüleri alındı ( $85 \mathrm{kVp}, 4.8 \mathrm{~mA}, 12$ sn ışınlama süresi ve $50 \times 80$ FOV alanı, kesit kalınlığı $0,2 \mathrm{~mm}$ ). KIBT görüntüleri 11 yıllık deneyime sahip Radyoloji Teknisyeni tarafından Ağız Diş ve Çene Radyolojisi Uzmanı gözetiminde çekildi.

Sino-nazal bölgede bulunan anatomik varyasyonlar ve patolojiler; Ağız Diş ve Çene Radyolojisi alanında sırasıyla 4 yıllık ve 15 yıllık deneyime sahip 2 gözlemci tarafından koronal kesit KIBT görüntülerinde araştırıldı. Yorgunluğa bağlı hata meydana gelmemesi için bir seferde en fazla 5 adet KIBT görüntüsü incelenerek, çalışma 3 haftalık bir süre içerisinde tamamlandı. Anteriordan posteriora doğru incelenen koronal kesit KIBT görüntülerinde her iki gözlemcinin ortak görüşü sağlanarak aşağıdaki anatomik varyasyon ve patolojiler var/yok olarak not edildi (Şekil 1).

- Septum deviasyonu (orta hattan $4 \mathrm{~mm}$ ve üstünde sapma) ${ }^{8}$,

- Konka bülloza,

- Haller hücresi,

- Orta ve alt konka varyasyonları,

- Maksiller sinüs patolojileri,

- Sinüs mukozasında kalınlaşma (sinüs tabanından $3 \mathrm{~mm}$ üzeri kalınlaşma). ${ }^{9}$

Ortak görüşe varılamayan vakalarda üçüncü bir gözlemciye (25 yıllık deneyime sahip) danışılarak fikir birliği sağlandı. Gözlemlerin tekrar edilebilirliğinin değerlendirilmesi için çalışmanın tamamlanmasından bir hafta sonra rastgele seçilen 20 KIBT görüntüsü tekrar iki gözlemci tarafından incelenerek anatomik varyasyon ve patolojiler not edildi. 


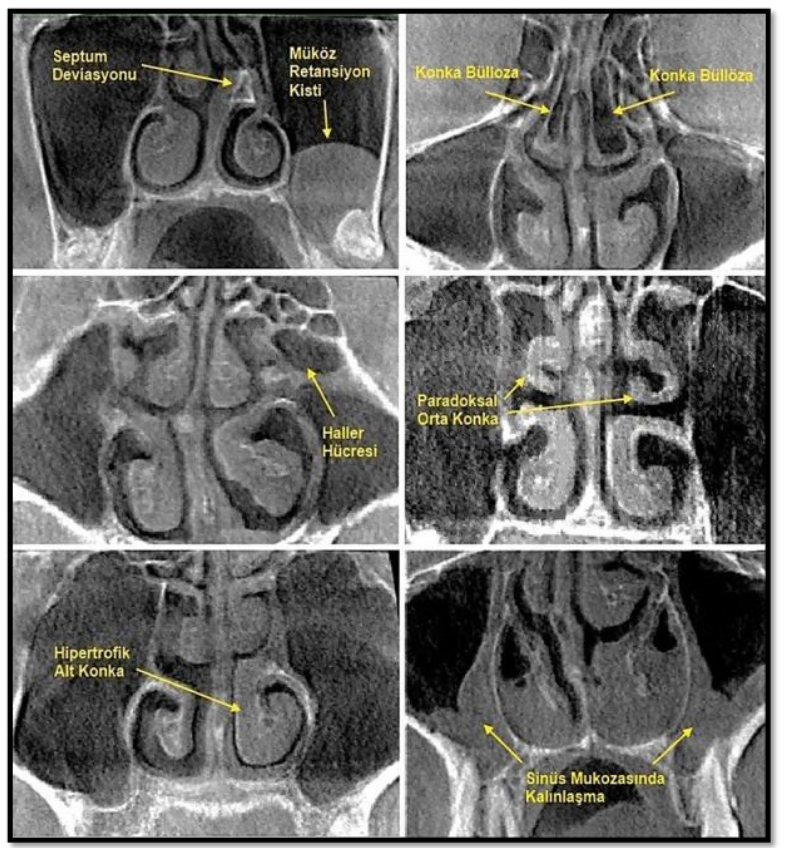

Şekil 1. Sino-nazal bölge CBCT görüntülerinde tespit edilen anatomik varyasyon ve patolojiler.

Hastaların demografik verileri, anket sonuçları ve sino-nazal bulgular SPSS 11.5 programına aktarıldı. Çalışma verileri değerlendirilirken niceliksel verilerin karşılaştırılmasında Oneway ANOVA ve Ki-Kare testi kullanıldı. Niteliksel verilerin karşılaştırılmasında ise Ttesti kullanıldı. Anlamlılı $\mathrm{p}<0.05$ düzeyinde değerlendirildi. Gözlemci-içi uyum Cohen Kappa Testi kullanılarak ölçüldü.

\section{SONUÇLAR}

Çalışmaya katılan 26'sı erkek ve 24'ü kadın toplam 50 hastanın yaşları 20-30 arasında değişmekte idi. Hastaların yaş ortalaması 23,9 \pm 2,43 olarak hesaplandı. Hastaların \% 44'ü aktif sigara içicisiydi. Hastaların risk grupları arası yaş ve cinsiyet dağılımda istatistiksel olarak anlamlı bir fark yoktu ( $p>0,05$ ). Epworth skoru ve sigara kullanım oranı risk grupları arasında anlamlı olarak farklılık gösterdi $(p<0,05)$ (Tablo 3). Sino-nazal bölgede anatomik varyasyon ve patoloji varlığı açısından risk grupları arasında istatistiksel olarak anlamlı bir fark bulunmadı. Ancak yüksek riskli hasta grubunda düşük riskli hasta grubuna göre maksiller sinüs mukozasında kalınlaşmaya daha sık rastlandı ( $p<0,05$ ) (Tablo 4). Gözlemlerin tekrar edilebilirliği $($ kappa $=0,9)$ mükemmel düzeyde bulundu.
Tablo 3. Hastaların yaş, cinsiyet dağılımı, Epworth skoru ve sigara kullanım oranının risk gruplarına göre karşılaştırıması

\begin{tabular}{|c|c|c|c|}
\hline & $\begin{array}{c}\text { Düşük Risk } \\
\text { Grubu }\end{array}$ & $\begin{array}{c}\text { Yüksek Risk } \\
\text { Grubu }\end{array}$ & \multirow{2}{*}{$\mathbf{P}$} \\
\hline & Ort \pm SS & Ort \pm SS & \\
\hline Yaş ${ }^{+}$ & $23,4 \pm 1,8$ & $24,5 \pm 2,8$ & 0,104 \\
\hline Cinsiyet $^{++}$ & N (\%) & N (\%) & \\
\hline Kadın & $14(\% 56)$ & $10(\% 40)$ & \multirow{2}{*}{0,258} \\
\hline Erkek & $11(\% 44)$ & $15(\% 60)$ & \\
\hline Epworth skoru ${ }^{+}$ & $3,7 \pm 2$ & $13,5 \pm 2,7$ & $0,000 *$ \\
\hline Sigara ${ }^{++}$ & N (\%) & N (\%) & \\
\hline Kullanıyor & $7(\% 28)$ & $15(\% 60)$ & \multirow{2}{*}{$0,023 *$} \\
\hline Kullanmıyor & $18(\% 72)$ & $10(\% 40)$ & \\
\hline
\end{tabular}

${ }^{+}$Oneway ANOVA testi, ${ }^{++}$Ki-kare testi, $* \mathrm{p}<0,05$

Tablo 4. Sino-nazal bölge CBCT görüntülerinde tespit edilen anatomik varyasyon ve patolojilerin risk gruplarına göre dağılımı.

\begin{tabular}{|c|c|c|c|c|}
\hline & & $\begin{array}{l}\text { Düşük Risk } \\
\text { Grubu } \\
\text { N (\%) }\end{array}$ & $\begin{array}{l}\text { Yüksek } \\
\text { Risk } \\
\text { Grubu } \\
\text { N (\%) }\end{array}$ & $\mathbf{P}$ \\
\hline \multirow{2}{*}{$\begin{array}{l}\text { Anatomik } \\
\text { Varyasyon/Patoloji }\end{array}$} & Var & $19(\% 76)$ & $19(\% 76)$ & \multirow{2}{*}{1,00} \\
\hline & Yok & $6(\% 24)$ & $6(\% 24)$ & \\
\hline \multirow{2}{*}{ Septum Deviasyonu } & Var & $7(\% 28)$ & $7(\% 28)$ & \multirow{2}{*}{1,00} \\
\hline & Yok & $18(\% 72)$ & $18(\% 72)$ & \\
\hline \multirow{2}{*}{ Konka Bülloza } & Var & $8(\% 32)$ & $7(\% 28)$ & \multirow{2}{*}{0,76} \\
\hline & Yok & $17(\% 68)$ & $18(\% 72)$ & \\
\hline \multirow{2}{*}{ Hipertrofik alt konka } & Var & $2(\% 8)$ & $1(\% 4)$ & \multirow{2}{*}{0,55} \\
\hline & Yok & $23(\% 92)$ & $24(\% 96)$ & \\
\hline \multirow{2}{*}{$\begin{array}{l}\text { Paradoksal orta } \\
\text { konka }\end{array}$} & Var & $1(\% 4)$ & $0(\% 0)$ & \multirow{2}{*}{0,31} \\
\hline & Yok & $24(\% 96)$ & $25(\% 100)$ & \\
\hline \multirow{2}{*}{ Haller Hücresi } & Var & $3(\% 12)$ & $4(\% 16)$ & \multirow{2}{*}{0,68} \\
\hline & Yok & $22(\% 88)$ & $21(\% 84)$ & \\
\hline \multirow{2}{*}{$\begin{array}{l}\text { Müköz Retansiyon } \\
\text { Kisti }\end{array}$} & Var & $4(\% 16)$ & $6(\% 24)$ & \multirow{2}{*}{0,48} \\
\hline & Yok & $21(\% 84)$ & $19(\% 76)$ & \\
\hline \multirow{2}{*}{$\begin{array}{l}\text { Sinüs mukozasında } \\
\text { kalınlaşma }\end{array}$} & Var & $1(\% 4)$ & $8(\% 32)$ & \multirow{2}{*}{ 0,01* } \\
\hline & Yok & $24(\% 96)$ & $17(\% 68)$ & \\
\hline
\end{tabular}

\section{TARTIŞMA}

Yalnızca klinik özellikler ile kesin OUAS tanısı koymak mümkün değildir. Klinik özelliklere dayalı değerlendirme ile tanı koyma olasılığı \%50 - 60 gibi düşük bir orandadır. Ancak iyi bir değerlendirme ile konulacak tanının, sınırlı PSG imkânlarında, hastaların uyku merkezlerine yönlendirilmesinde önemi büyüktür. ${ }^{10}$

OUAS teşhisinde en çok kullanılan anketler BA ve EUÖ'dir. Bu anketlerin kullanılmasının sebebi risk

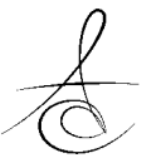


faktörleri üzerine yoğunlaşan basit sorulardan oluşmasıdır. BA'nın hassasiyet (sensitivity) ve seçiciliğinin (specifity) değerlendirildiği çeşitli çalışmalarda; hassasiyet: \%62-85 arası, seçicilik: \%43-65 arası olarak bulunmuştur. Ahmadi ve ark. ${ }^{11}$ BA'yı tahmin edici değeri düşük bir test olarak rapor etmişlerdir. Buna karşın Gus ve ark. ${ }^{12}$, Kang ve ark. ${ }^{13}$ ve Bouloukaki ve ark. ${ }^{14}$ ise BA'nın OUAS açısından yüksek riskli hastaların belirlenmesinde yararlı ve kullanılabilir bir test olduğunu bildirmişlerdir.

EUÖ skorları ve OUAS arasındaki ilişkiyi inceleyen Karakoç ve ark. ${ }^{15}$, Kayım ve ark. ${ }^{16}$, Uyar ve ark. $^{17}$ değerler arasında anlamlı bir ilişki olduğunu bulmuştur. Bunun yanında EUÖ'nün tahmin edici değerinin düşük olduğu ve OUAS teşhisinde tek başına kullanılmaması gerektiği bildirilmiştir. $\mathrm{Bu}$ nedenle çalışmamızda da riskli hastaların belirlenmesinde 2 anket birlikte kullanılmıştır.

Ortalama EUÖ skorları toplumların ankette sorgulanan sekiz farklı günlük aktiviteyi yapma olasılıklarına bağlı olarak farklılıklar gösterebilir. Kitap okuma alışkanlığı olmayan bir kişinin bu durumda uykuya dalma olasılığını doğru olarak cevaplaması beklenemez. Yine araba kullanmayan bir kişi trafikte birkaç dakika durduğu takdirde uykuya dalma olasılığını tam olarak değerlendiremeyebilir. Aynı şekilde sinema ve tiyatro seyretme alışkanlığı bulunmayan bir kişi de net cevaplar veremeyecektir. Bu sebeple kişilerin ve toplumların bu sorulara yanıtları sosyokültürel ve ekonomik durumlarına bağlı olarak değişebilir. ${ }^{15}$ Ayrıca BA'da yer alan horlama ve solunum durması ile ilgili sorulara hastalar tek başına doğru cevap veremeyebilir. Bu sebeple hastaların anketleri beraber ikamet ettikleri yakınları ile doldurulması önerilmektedir. ${ }^{18}$ Çalışmamızda da hastaların sorulara daha doğru cevap verebilmesi için anketler hasta yakınları ile birlikte doldurulmuştur.

Burun erişkin insanlarda üst hava yolu direncinin yaklaşık \%70'ni oluşturur ve uyanıklık süresince en büyük üst solunum yolu direnç bölümüdür. OUAS'lı hastalarda da burunda septum deviasyonu, konka hipertrofisi, büllöz konka gibi varyasyonlar bulunduğunda nazal hava yolları daralmakta ve semptomlarda artma olabilmektedir. ${ }^{2}$ Özellikle devamlı pozitif havayolu basıncı (CPAP) tedavisi gören hastalarda nazal tıkanıklık tedavide zorluk oluşturmaktadır.
Enciso ve ark. ${ }^{19}$ şiddetli ve orta seviyede OUAS hastaları ve kontrol grubunda baş boyun bölgesi CBCT bulgularını karşılaştırmışlardır. Sonuç olarak hasta grupları arasında septum deviasyonu, konka bülloza, konka hipertrofisi, sinüs mukozasında kalınlaşma/sinüzit, mükoz retansiyon kisti ve polip varlığı açısından istatistiksel olarak anlamlı bir fark bulamamışlardır. Ancak OUAS hastalarında bu bulgulara daha sık rastlanıldığını belirtmişlerdir. Çağlayan ve Tozoğlu ${ }^{20}$ içerisinde OUAS hastalarının da bulunduğu toplam 207 hastanın CBCT görüntülerini incelemiş ve maksillofasiyal bölgede en sık mukozal kalınlaşma tespit etmiştir.

Park ve ark. ${ }^{21}$ OUAS teşhisi konmuş 25 hastaya nazal cerrahi uygulamış ve sonrasında AHI skorlarında önemli bir düşüş bulmuştur. Hastaların \% 56'sında OUAS'ın şiddetinde azalma görülmüştür. Buna karşın Virkkula ve ark. ${ }^{22}$ nazal cerrahinin uyku parametrelerinde önemli bir düzelmeye neden olmadığını ve OUAS'ta düzelme sağlamadığını söylemiştir. Özmen ve Onart $^{23}$ ise nazal cerrahinin sübjektif yakınmalarda düzelme sağladığını ancak AHI skorlarında düzelme sağlamadığını bildirmiştir. Rombaux ve ark. ${ }^{24}$ nazal cerrahinin OUAS tedavisinde sadece yüzde 20 başarı sağladığını, hatta bazı durumlarda hastalığı daha da şiddetlendirdiği söylemiş ve nazal cerrahinin sadece CBAP tedavisinde zorlanan hastalara uygulanması gerektiğini bildirmiştir.

Çalışmamızda da risk grupları arasında nazal bölgede bulunan anatomik varyasyonlar açısından istatistiksel olarak anlamlı bir fark bulunmamıştır. Ancak yüksek riskli grupta maksiller sinüs mukozasında kalınlaşma daha sık görülmüştür. Uyku sırasında hava yollarında oluşan daralmanın negatif hava basıncı oluşturarak mukozalarda enflamasyona neden olduğu düşünülmektedir. Bunun yanında yüksek risk grubunda sigara kullanımının fazla olması mukozalarda meydana gelen enflamasyonun önemli bir sebebi sayılabilir.

Sonuç olarak sino-nazal bölgede obstrüksiyon meydana getiren ve OUAS için risk oluşturduğu belirtilen anatomik varyasyonlar açısından $\mathrm{CBCT}^{\prime}$ de risk grupları arası anlamlı fark bulunamamıştır. Buna bağlı olarak OUAS'lı bireylerde sinonazal bölge varyasyonlarının primer risk faktörü olarak değerlendirilemeyeceği ve nazal cerrahinin sadece seçili hastalara uygulanması gerektiğini düşünmekteyiz. 


\section{KAYNAKLAR}

1. Karakış D, Yıldırım Biçer AZ, Gülepe E. Obstrüktif Uyku Apnesi Olan Bir Hastanın Alt Çeneyi Öne Konumlandırıcı Aparey ile Tedavisi: Vaka Raporu. Atatürk Üniv Diş Hek Fak Derg 2013; 23: 385-90.

2. Demir A, Ursavaş A, Aslan AT, Gülbay B, Çiftçi B, Çuhadaroğlu Ç, Keyf F, Fırat H, Yılmaz M, Gerek M, Köktürk O, İtil O, Karakoç O, Kaçmaz Başoğlu O, Ersu R, Ardıç S, Öktem S, Güven SF, Ulukavak Çiftçi T. Türk Toraks Derneği obstrüktif uyku apne sendromu tanı ve tedavi uzlaşı raporu. Turkish Thoracic Journal 2012; 13: 1-66.

3. Schwab RJ, Remmers JE, Kuna ST. Anatomy and Physiology of Upper Airway Obstruction. In: Principles and Practice of Sleep Medicine. Ed. Kryger MH, Roth T, Dement WC, Missouri, Elsevier Saunders 2011; p: 1153-71.

4. Kohler M, Bloch KE, Stradling JR. The role of the nose in the pathogenesis of obstructive sleep apnoea and snoring. Eur Respir J 2007; 30: 120815.

5. Chesson AL, Ferber RA, Fry JM, Grigg-Damberger M, Hartse KM, Hurwitz TD, Johnson S, Kader GA, Littner M, Rosen G, Sangal RB, Schmidt-Nowara $W$, Sher A. Practice parameters for the indications for polysomnography and related procedures. An American Academy of Sleep Medicine Report: Standards of Practice Committee of the American Academy of Sleep Medicine. Sleep 1997; 20: 40622.

6. Güzel GK, Meşe A, Tanrıkulu T. Obstrüktif Uyku Apnesi Sendromunun Tedavisinde Protetik Yaklaşım: Olgu Sunumu. Atatürk Üniv Diş Hek Fak Derg 2011; 4: 86-91.

7. Cömert MA. Rem ilişkili uykuda solunum bozukluğunun klinik ve polisomnografik özelliklerinin belirlenmesi ve izlemde saptanacak değişikliklerin karşılaştırılması. Uzmanlık Tezi. T.C. Sağlık bakanlığı Süreyyapaşa Göğüs Hastalıkları ve Göğüs Cerrahisi Eğitim ve Araştırma Hastanesi. 2009.

8. Smith KD, Edwards PC, Saini TS, Norton NS. The prevalence of concha bullosa and nasal septal deviation and their relationship to maxillary sinusitis by volumetric tomography. International Journal Of Dentistry 2010; 2010: 1-5.
9. Balcı A, Akoğlu E, Karazincir S, Okuyucu S, Karazincir O, Okuyucu E, Altıntaş Y. Manyetik Rezonans Görüntülemede Rastlantısal Paranazal Sinüs Patolojilerinin Sıklığı ve Hasta Semptomları İle İlişkisi. KBB-Forum 2007; 6: 90-3.

10. Sarı H. Obstrüktif uyku apne sendromlu hastalarda vücut kitle indeksi ve boyun çevresi ölçümlerinin apne hipopne indeksiyle korelasyonu. Uzmanlık Tezi. T.C. Sağlık bakanlığı, Göztepe Eğitim ve Araştırma Hastanesi Kulak Burun Boğaz Kliniği. 2008.

11. Ahmadi N, Chung SA, Gibbs A, Shapiro CM. The Berlin questionnaire for sleep apnea in a sleep clinic population: relationship to polysomnographic measurement of respiratory disturbance. Sleep Breath, 2008; 12: 39-45.

12. Gus M, Gonçalves SC, Martinez D, De Abreu Silva EO, Moreira LB, Fuchs SC, Fuchs FD. Risk for Obstructive Sleep Apnea by Berlin Questionnaire, but not daytime sleepiness, is associated with resistant hypertension: a case-control study. Am J Hypertens 2008; 21: 832-5.

13. Kang K, Park KS, Kim JE, Kim SW, Kim YT, Kim JS, Lee HW. Usefulness of the Berlin Questionnaire to identify patients at high risk for obstructive sleep apnea: a population-based door-to-door study. Sleep Breath 2013; 17: 803-10.

14. Bouloukaki I, Komninos ID, Mermigkis C, Micheli K, Komninou M, Moniakı V, Mauroudi E, Siafakas NM, Schiza SE. Translation and validation of Berlin questionnaire in primary health care in Greece. BMC Pulm Med 2013; 13: 6.

15. Karakoç Ö, Akçam T, Gerek M, Birkent H. Horlama ve Obstüriktif Uyku Apneli Hastalarda Epworth Uykululuk Skalasının Güvenilirliği KBB-Forum 2007; 6: 86-9.

16. Kayım Ö, Yüksekkaya E, Akhan G. Obstrüktif Uyku Apne Sendromunda Aşırı Gündüz Uykululuğu Ve Uyku Yapısı İle İlişkisi. C.Ü. Tıp Fakültesi Dergisi 2007; 29: 62-8.

17. Uyar M, Elbek O, Aydın N, Çifçi N, Bayram N, Fakılı F, Gündoğdu N, Dikensoy Ö. Clinical Profiles of Obstructive Sleep Apnea Syndrome. Turk Toraks Der 2008; 9: 113-6. 
18. Sagaspe P, Leger D, Taillard J, Bayon V, Chaumet G, Philip P. Might the Berlin Sleep Questionnaire applied to bed partners be used to screen sleep apneic patients? Sleep Med 2010; 11: 479-83.

19. Enciso R, Shigeta $Y$, Nguyen M, Clark GT. Comparison of cone-beam computed tomography incidental findings between patients with moderate/severe obstructive sleep apnea and mild obstructive sleep apnea/healthy patients. Oral Surgery, Oral Medicine, Oral Pathology and Oral Radiology 2012; 114: 373-81.

20. Çağlayan F, Tozoğlu U. Incidental findings in the maxillofacial region detected by cone-beam CT. Diagn Interv Radiol 2012; 18: 159-63.

21. Park CY, Hong JH, Lee JH, Lee KE, Cho HS, Lim SJ, Kwak JW, Kim SK, Kim HJ. Clinical Effect of Surgical Correction for Nasal Pathology on the Treatment of Obstructive Sleep Apnea Syndrome. PloS one 2014; 9; e98765.

22. Virkkula $P$, Bachour $A$, Hytonen $M$, Salmit, Malmberg $\mathrm{H}$, Hurmerinta, $\mathrm{K}$, Maasilta $\mathrm{P}$. Snoring is not relieved by nasal surgery despite improvement in nasal resistance. Chest 2006; 129: 81-7.

23. Özmen ÖA, Onart S. Treatment Of Obstructıve Sleep Apnea Syndrome: Nasal Surgery. Turkiye Klinikleri J Surg Med Sci 2007; 3: 90-2.

24. Rombaux P, Liistro G, Hamoir $M$, Bertrand $B$, Aubert G, Verse T, Rodenstein D. Nasal obstruction and its impact on sleep-related breathing disorders. Rhinology 2005; 43: 242-50.

\author{
Yazışma Adresi: \\ Yrd.Doç.Dr.Mehmet Zahit ADIŞEN \\ Kırıkkale Üniversitesi, \\ Diş Hekimliği Fakültesi \\ Kurtuluş Mahallesi 692. Sokak No:31 \\ Merkez / KIRIKKALE \\ TIf: +903182244927 \\ e-mail: m_zahit@hotmail.com
}

